\title{
1 Hot-rolled steel and steel-concrete composite design 2 incorporating strain hardening
}

3

4 L. Gardner ${ }^{1}$, X. Yun*1, L. Macorini ${ }^{1}$, M. Kucukler ${ }^{1}$

$5 \quad{ }^{1}$ Department of Civil and Environmental Engineering, Imperial College London, South

6 Kensington Campus, London, UK

7

8

9

Abstract: Current design codes for steel and steel-concrete composite structures are based on elastic, perfectly plastic material behaviour and can lead to overly conservative strength predictions due to the neglect of the beneficial influence of strain hardening, particularly in the case of stocky, bare steel cross-sections and composite beams under sagging bending moments. The Continuous Strength Method (CSM) is a deformation based design method that enables material strain hardening properties to be exploited, thus resulting in more accurate capacity predictions. In this paper, a strain hardening material model, which can closely represent the stress-strain response of hot-rolled steel, is introduced and incorporated into the CSM design framework. The CSM cross-section resistance functions, incorporating strain hardening, are derived for hot-rolled steel sections in compression and bending, as well as hot-rolled steelconcrete composite sections where their neutral axes lie within the concrete slab in bending. Comparisons of the capacity predictions with a range of experimental data from the literature and finite element data generated herein demonstrate the applicability and benefits of the proposed approach.

Keywords: Composite beams, Continuous strength method, Deformation based design, Hotrolled steel, Steel structures. 


\section{Introduction}

28 The concept of cross-section classification is used in current design codes to determine the appropriate structural design resistance of metallic sections. The method limits the maximum stress in the cross-section to the yield stress $f_{\mathrm{y}}$, neglecting the beneficial effects of strain hardening. Experimental results have shown that the current design methods, based on the idealised elastic, perfectly plastic material behaviour, are often conservative in estimating the resistance of stocky hot-rolled steel cross-sections in both compression and bending [1-3] and composite beams under sagging bending moments [4-6]. The Continuous Strength Method (CSM) is a newly developed deformation based approach to steel design that provides an alternative treatment to cross-section classification, and enables the effective utilization of strain hardening. The method was originally developed for stainless steel structural elements [7-9], which exhibit a high degree of strain hardening, and the same concept has since been applied to structural carbon steel [10-12] and aluminium alloy [13] design.

A bi-linear (elastic-linear hardening) material model has been employed in the CSM to date, providing consistency and a satisfactory representation for design purposes of the observed stress-strain responses of cold-formed steel, stainless steel and aluminium alloys $[9,12,13]$. However, due to the existence of a yield plateau, this CSM bi-linear material model is less suitable for hot-rolled carbon steel. Thus, a revised CSM material model is proposed for hotrolled carbon steel that exhibits a yield point, a yield plateau and a strain hardening region. In this paper, the application of the CSM to bare hot-rolled structural steel elements, focusing primarily on cross-sections in compression and bending, including recent developments and comparisons with test results, is outlined. Extension of the method to composite beams under sagging bending moments is then described. 


\section{Application of the CSM to hot-rolled steel elements}

The key characteristics of the CSM lie in the employment of a base curve that defines the maximum level of strain $\varepsilon_{\mathrm{csm}}$ that a cross-section can endure prior to failure by (inelastic) local buckling and the adoption of a material model that allows for strain hardening.

\subsection{CSM design base curve}

The CSM design base curve provides a continuous relationship between the strain ratio $\varepsilon_{\mathrm{csm}} / \varepsilon_{\mathrm{y}}$ and the cross-section slenderness $\bar{\lambda}_{\mathrm{p}}$, where $\varepsilon_{\mathrm{y}}$ is the yield strain of the material equal to $f_{\mathrm{y}} / E$, with $f_{\mathrm{y}}$ being the material yield strength and $E$ being the Young's modulus. Within the CSM, the cross-section slenderness $\bar{\lambda}_{p}$ is defined in non-dimensional form as the square root of the ratio of the yield stress $f_{\mathrm{y}}$ to the elastic buckling stress $\sigma_{\mathrm{cr}}$, as given by Eq. (1). The elastic buckling stress $\sigma_{\mathrm{cr}}$ should be determined for the full cross-section either using numerical methods, such as the finite strip software CUFSM [14], or approximate analytical methods [15]. As a conservative alternative, the elastic buckling stress of the full cross-section may be taken as that of its most slender element using the classical plate buckling expression [16]. The former approach considers plate element interaction effects within the cross-section, as used in the direct strength method [17], whereas the classical plate buckling expression assumes simply supported conditions at the edges of the adjoining plates, which neglects element interaction and generally results in a conservative prediction of $\sigma_{\mathrm{cr}}$. More favourable results are obtained when the effects of plate element interaction are considered, and this is therefore recommended, and adopted in the analyses performed herein by calculating $\sigma_{\mathrm{cr}}$ using CUFSM [14]. The CSM design base curve is given by Eq. (2), where $\varepsilon_{\mathrm{u}}$ is the strain corresponding to the ultimate tensile stress $f_{\mathrm{u}}$. Two upper bounds have been placed on the predicted cross-section deformation capacity $\varepsilon_{\mathrm{csm}} / \varepsilon_{\mathrm{y}}$; the first limit of 15 corresponds to the material ductility requirement expressed in EN 1993-1-1 [18] and prevents excessive deformations and the second limit of $\mathrm{C}_{1} \varepsilon_{\mathrm{u}} / \varepsilon_{\mathrm{y}}$, where 
$77 \quad \mathrm{C}_{1}$ is a coefficient corresponding to the adopted CSM material model as described in the next section, defines a 'cut-off' strain to prevent over-predictions of material strength. It is noted that the CSM does not currently apply to cross-sections where $\bar{\lambda}_{\mathrm{p}}>0.68$, which is the boundary between slender and non-slender sections [9], though developments are underway in this area.

$$
\bar{\lambda}_{\mathrm{p}}=\sqrt{f_{\mathrm{y}} / \sigma_{\mathrm{cr}}}
$$

$$
\frac{\varepsilon_{\mathrm{csm}}}{\varepsilon_{\mathrm{y}}}=\frac{0.25}{\bar{\lambda}_{\mathrm{p}}^{3.6}} \text { but } \frac{\varepsilon_{\mathrm{csm}}}{\varepsilon_{\mathrm{y}}} \leq \min \left(15, \frac{\mathrm{C}_{1} \varepsilon_{\mathrm{u}}}{\varepsilon_{\mathrm{y}}}\right)
$$

\subsection{Material model}

An elastic, linear hardening material model has been adopted in the CSM to represent the strain hardening response of metallic materials, such as cold-formed steel, stainless steel and aluminium alloys. Despite the fact that the actual observed stress-strain response of these materials is rounded, the elastic, linear hardening CSM material model has been shown to capture the general strain hardening behaviour sufficiently well to enable accurate design capacity predictions $[9,12,13]$. However, this bi-linear material model is less suitable for hotrolled carbon steel due to the presence of the characteristic yield plateau, with strain hardening not commencing until the attainment of the strain hardening strain $\varepsilon_{\text {sh. }}$ Thus, a revised quadlinear material model, as illustrated in Fig. 1, is proposed for hot-rolled carbon steel considering both the length of the yield plateau and the strain hardening modulus $E_{\text {sh. }}$.

The adopted stress-strain model consists of four stages and can be written over the full range of tensile strains as: 


$$
f(\varepsilon)= \begin{cases}E \varepsilon & \text { for } \varepsilon \leq \varepsilon_{\mathrm{y}} \\ f_{\mathrm{y}} & \text { for } \varepsilon_{\mathrm{y}} \leq \varepsilon \leq \varepsilon_{\mathrm{sh}} \\ f_{\mathrm{y}}+E_{\mathrm{sh}}\left(\varepsilon-\varepsilon_{\mathrm{sh}}\right) & \text { for } \varepsilon_{\mathrm{sh}} \leq \varepsilon \leq \mathrm{C}_{1} \varepsilon_{\mathrm{u}} \\ f_{\mathrm{C}_{1} \varepsilon_{\mathrm{u}}}+\frac{f_{\mathrm{u}}-f_{\mathrm{C}_{1} \varepsilon_{\mathrm{u}}}}{\varepsilon_{\mathrm{u}}-\mathrm{C}_{1} \varepsilon_{\mathrm{u}}}\left(\varepsilon-\mathrm{C}_{1} \varepsilon_{\mathrm{u}}\right) & \text { for } \mathrm{C}_{1} \varepsilon_{\mathrm{u}} \leq \varepsilon \leq \varepsilon_{\mathrm{u}}\end{cases}
$$

104 in which $\mathrm{C}_{1} \varepsilon_{\mathrm{u}}$ represents the strain at the intersection point of the third stage of the model and

105 the actual stress-strain curve, and $f_{\mathrm{C}_{1} \varepsilon_{u}}$ is the corresponding stress, as shown in Fig. 1. Two 106 material coefficients, $\mathrm{C}_{1}$ and $\mathrm{C}_{2}$, are used in the material model. $\mathrm{C}_{1}$ represents the interaction 107 point discussed previously and effectively defines a 'cut-off' strain to avoid over-predictions 108 of material strength and is included in the base curve (Eq. (2)); $\mathrm{C}_{2}$ is used in Eq. (4) to define 109 the strain hardening slope $E_{\text {sh. }}$.

$$
E_{\mathrm{sh}}=\frac{f_{\mathrm{u}}-f_{\mathrm{y}}}{\mathrm{C}_{2} \varepsilon_{\mathrm{u}}-\varepsilon_{\mathrm{sh}}}
$$

113 Coupon test data on hot-rolled carbon steels from a series of existing experimental programs

$114[1,3,11,19-31]$ were collected and analysed to establish predictive expressions for $\varepsilon_{\mathrm{u}}, \varepsilon_{\mathrm{sh}}$ and

115 the material coefficients $\mathrm{C}_{1}$ and $\mathrm{C}_{2}$.

117 For the strain at the ultimate tensile stress $\varepsilon_{\mathrm{u}}$, a comparison between the collected test data and

118 the predictive expression (Eq. (5)) is shown in Fig. 2. The comparison reveals good agreement

119 between the predictive expression and the test data for both hot-rolled and cold-formed

120 material, with a mean ratio of the predicted to test value of $\varepsilon_{\mathrm{u}}$ of 0.95 , and a moderate coefficient

121 of variation (COV) of 0.41 . For the high strength steel, with high ratios of yield stress to 
122 ultimate stress, the predictive expression given by Eq. (5) tends to underestimate the measured 123 ductility (strain at ultimate stress $\varepsilon_{\mathrm{u}}$ ) of hot-rolled material by a factor of more than 2, though

124 the absolute differences are relatively small. Test data for high strength hot-rolled carbon steel 125 are fairly scarce and more test data are required to further verify Eq. (5).

126

$$
\varepsilon_{\mathrm{u}}=0.6\left(1-\frac{f_{\mathrm{y}}}{f_{\mathrm{u}}}\right)
$$

129 The ratio of strain hardening stain $\varepsilon_{\mathrm{sh}}$ to ultimate strain $\varepsilon_{\mathrm{u}}$ is plotted against the ratio of yield 130 stress $f_{\mathrm{y}}$ to ultimate stress $f_{\mathrm{u}}$ in Fig. 3, in which the triangular points represent the test data where 131 the corresponding $\varepsilon_{\mathrm{u}}$ value was not reported in the literature but was instead predicted using 132 Eq. (5). Utilising regression analysis, the following predictive relationship between $\varepsilon_{\mathrm{sh}} / \varepsilon_{\mathrm{u}}$ and $133 f_{\mathrm{y}} / f_{\mathrm{u}}$ is proposed:

$$
\frac{\varepsilon_{\mathrm{sh}}}{\varepsilon_{\mathrm{u}}}=\left(\frac{f_{\mathrm{y}}}{f_{\mathrm{u}}}\right)^{7}
$$

137 Similarly, using least squares regression of the available experimental stress-strain curves on

138 hot-rolled steel, the material coefficients $\mathrm{C}_{1}$ and $\mathrm{C}_{2}$ may be obtained from the following predictive expressions:

140

$$
\mathrm{C}_{1}=\frac{\varepsilon_{\mathrm{sh}}+0.25\left(\varepsilon_{\mathrm{u}}-\varepsilon_{\mathrm{sh}}\right)}{\varepsilon_{\mathrm{u}}}
$$

$$
\mathrm{C}_{2}=\frac{\varepsilon_{\mathrm{sh}}+0.4\left(\varepsilon_{\mathrm{u}}-\varepsilon_{\mathrm{sh}}\right)}{\varepsilon_{\mathrm{u}}}
$$


144 A detailed description of the quad-linear material model and its validation against further

145 collected experimental stress-strain curves is currently being prepared.

146

147 2.3. Cross-section resistance

148 Within the CSM design framework, cross-section resistance is determined utilizing the strain

149 ratio $\varepsilon_{\mathrm{csm}} / \varepsilon_{\mathrm{y}}$ from the design base curve (Eq. (2)), together with the adopted material model. In

150 this paper, the quad-linear material model for hot-rolled steel, described in Section 2.2, is

151 employed.

152

153 For non-slender cross-sections $\left(\bar{\lambda}_{p} \leq 0.68\right)$, the CSM axial compressive resistance $N_{\mathrm{csm}, \mathrm{Rd}}$ is

154 calculated as the product of the gross cross-sectional area A and the CSM limiting material 155 stress $f_{\text {csm }}$, as given by Eq. (9), in which $\gamma_{\mathrm{M} 0}$ is a partial safety factor for cross-section resistance

156 with a recommended value of unity for steel elements [18] and $f_{\text {csm }}$ may be calculated from Eq.

157 (10) based on the proposed material model. Note that only the second and third stages of the

158 quad-linear model are used in the CSM, since currently the method applies to non-slender 159 cross-sections $\left(\varepsilon_{\mathrm{csm}} / \varepsilon_{\mathrm{y}} \geq 1\right)$, and progression into the fourth stage would correspond to very high

160 strains and lead to overly complicated resistance functions, particularly in bending.

161

$$
N_{\mathrm{csm}, \mathrm{Rd}}=\frac{\mathrm{A} f_{\mathrm{csm}}}{\gamma_{\mathrm{M} 0}}
$$

163

164

$$
f_{\mathrm{csm}}= \begin{cases}f_{\mathrm{y}} & \text { for } \varepsilon_{\mathrm{y}} \leq \varepsilon_{\mathrm{csm}} \leq \varepsilon_{\mathrm{sh}} \\ f_{\mathrm{y}}+E_{\mathrm{sh}}\left(\varepsilon_{\mathrm{csm}}-\varepsilon_{\mathrm{sh}}\right) & \text { for } \varepsilon_{\mathrm{sh}}<\varepsilon_{\mathrm{csm}} \leq \mathrm{C}_{1} \varepsilon_{\mathrm{u}}\end{cases}
$$


166 For sections with $\bar{\lambda}_{\mathrm{p}} \leq 0.68$, the cross-section resistance in bending $M_{\mathrm{csm}, \mathrm{Rd}}$ depends upon

167 whether or not strain hardening is experienced (i.e. whether or not $\varepsilon_{\mathrm{csm}}>\varepsilon_{\mathrm{sh}}$ ). If $\varepsilon_{\mathrm{csm}} \leq \varepsilon_{\mathrm{sh}}$, then 168 the cross-section bending resistance $M_{\mathrm{csm}, \mathrm{Rd}}$ is given by Eqs. (11) and (12) for major and minor 169 axis bending, respectively, where $W_{\mathrm{pl}}$ is the plastic section modulus, $W_{\mathrm{el}}$ is the elastic section 170 modulus, $\mathrm{y}$ and $\mathrm{z}$ refer to the major and minor axes, respectively, and $\alpha$ is a dimensionless coefficient that depends on the type of section and axis of bending as defined in Table 1. These expressions allow for the increasing resistance with increasing deformation capacity (i.e. strain

173 ratio $\left.\varepsilon_{\mathrm{csm}} / \varepsilon_{\mathrm{y}}\right)$ due to the spread of plasticity.

174

$$
M_{\mathrm{y}, \mathrm{csm}, \mathrm{Rd}}=\frac{W_{\mathrm{pl}, \mathrm{y}} f_{\mathrm{y}}}{\gamma_{\mathrm{M} 0}}\left[1-\left(1-\frac{W_{\mathrm{el}, \mathrm{y}}}{W_{\mathrm{pl}, \mathrm{y}}}\right) /\left(\frac{\varepsilon_{\mathrm{csm}}}{\varepsilon_{\mathrm{y}}}\right)^{\alpha}\right] \quad \text { for } \varepsilon_{\mathrm{csm}} \leq \varepsilon_{\mathrm{sh}}
$$

$$
M_{\mathrm{z}, \mathrm{csm}, \mathrm{Rd}}=\frac{W_{\mathrm{pl}, \mathrm{z}} f_{\mathrm{y}}}{\gamma_{\mathrm{M} 0}}\left[1-\left(1-\frac{W_{\mathrm{el}, \mathrm{z}}}{W_{\mathrm{pl}, \mathrm{z}}}\right) /\left(\frac{\varepsilon_{\mathrm{csm}}}{\varepsilon_{\mathrm{y}}}\right)^{\alpha}\right] \quad \text { for } \varepsilon_{\mathrm{csm}} \leq \varepsilon_{\mathrm{sh}}
$$

For the more stocky cross-sections, where $\varepsilon_{\mathrm{csm}}>\varepsilon_{\mathrm{sh}}$, some benefit from strain hardening can

180 also be exploited, and the CSM cross-section bending resistance is given by Eqs. (13) and (14),

181 for major axis and minor axis bending, respectively, where $\beta$ is a dimensionless coefficient, values of which are given in Table 1.

183

$$
M_{\mathrm{y}, \mathrm{csm}, \mathrm{Rd}}=\frac{W_{\mathrm{pl}, \mathrm{y}} f_{\mathrm{y}}}{\gamma_{\mathrm{M} 0}}\left[1-\left(1-\frac{W_{\mathrm{el}, \mathrm{y}}}{W_{\mathrm{pl}, \mathrm{y}}}\right) /\left(\frac{\varepsilon_{\mathrm{csm}}}{\varepsilon_{\mathrm{y}}}\right)^{\alpha}+\beta\left(\frac{\varepsilon_{\mathrm{csm}}-\varepsilon_{\mathrm{sh}}}{\varepsilon_{\mathrm{y}}}\right)^{2} \frac{E_{\mathrm{sh}}}{E}\right] \quad \text { for } \varepsilon_{\mathrm{csm}}>\varepsilon_{\mathrm{sh}}
$$

$$
M_{\mathrm{z}, \mathrm{csm}, \mathrm{Rd}}=\frac{W_{\mathrm{pl}, \mathrm{z}} f_{\mathrm{y}}}{\gamma_{\mathrm{M} 0}}\left[1-\left(1-\frac{W_{\mathrm{el}, \mathrm{z}}}{W_{\mathrm{pl}, \mathrm{z}}}\right) /\left(\frac{\varepsilon_{\mathrm{csm}}}{\varepsilon_{\mathrm{y}}}\right)^{\alpha}+\beta\left(\frac{\varepsilon_{\mathrm{csm}}-\varepsilon_{\mathrm{sh}}}{\varepsilon_{\mathrm{y}}}\right)^{2} \frac{E_{\mathrm{sh}}}{E}\right] \quad \text { for } \varepsilon_{\mathrm{csm}}>\varepsilon_{\mathrm{sh}}
$$




\subsection{Comparison with test data and design methods}

189 The resulting predictions from the CSM have been compared with experimental data on 20

190 hot-rolled carbon steel stub columns [1,2,11] and 97 beams [1,3,11,32-35]. All comparisons

191 are made on the basis of the measured geometric and material properties and with all partial

192 factors set equal to unity. The average ratios of ultimate test loads $N_{\text {test }}$ and moments $M_{\text {test }}$ to

193 the CSM $\left(N_{\mathrm{csm}}, M_{\mathrm{csm}}\right)$ and EN 1993-1-1 ( $\left.N_{\mathrm{EC}}, M_{\mathrm{EC}}\right)$ predicted resistances have been determined

194 and are summarized in Table 2. The coefficients of variation (COV) have also been calculated

195 to quantify the scatter of the predictions, and are presented in Table 2. It can be seen that the

196 CSM provides more accurate and consistent predictions compared with those from EN 1993-

197 1-1 [18], especially in the bending predictions for the Class 3 cross-sections where an average

198 of $9 \%$ enhancement in capacity can be obtained using the CSM due to its accurate consideration

199 of the spread of plasticity. Further research is currently underway into refining the material

200 model, incorporating a larger pool of data on hot-rolled carbon steel material and cross-

201 sections, and reliability analysis.

202

203 3. Application of the CSM to composite beams

204 3.1. Background

205 Steel-concrete composite construction seeks to harness the combined merits of the two

206 materials to enable more efficient and economical structural solutions. The case of simply

207 supported composite beams under sagging bending moment, whereby the concrete is largely

208 in compression and the steel in tension, offers the greatest opportunity to exploit the full

209 capacity of both materials. Composite beams having a ductile cross-section, defined as one in

210 which the geometrical and material properties are such that strain hardening of the lower flange

211 occurs before the collapse moment is reached, are desirable in engineering applications since

212 the full plastic moment capacity can be utilized. Current design codes for composite structures, 
213 including EN 1994-1-1 [36], employ simple rigid plastic analysis to calculate the cross-section

214 bending capacity of composite beams and, as for the design of bare steel beams, strain

215 hardening effects in the steel are usually neglected. This can be rather conservative, as shown

216 in several experimental and numerical studies [4,6], where substantial benefits from strain

217 hardening have been observed. Note that the influence of strain hardening is implicitly included

218 in the determination of the minimum degree of shear connection required to achieve the plastic

219 bending resistance of composite beams in Eurocode 4 [37], but increases in load-bearing

220 capacity for beams with full shear connection, beyond those derived from rigid-plastic theory,

221 are not accounted for.

222

223 The focus of this section of the paper is on the assessment of Eurocode 4 and the development of a more efficient method for the design of composite beams under sagging bending moment, based on the results of existing experiments and numerical simulations. An analytical model is developed to calculate the bending capacity of composite beams with full shear connection, allowing for the influence of strain hardening through the quad-linear material model introduced in Section 2.2. Comparisons of the resistances obtained from the proposed design expressions with test results are made to demonstrate the accuracy and benefits of the method. Finally, a two-dimensional finite element (FE) model is established and validated against experimental results reported elsewhere. Upon validation of the FE models, parametric studies are performed to investigate the response of composite beams with partial shear connection, considering the effects of the steel grade and degree of partial shear connection. An indicative design approach is then proposed. 


\subsection{Full shear connection}

239 In the case of composite beams with full shear connection, where the shear connection deformability is small, a single neutral axis exists and the bending resistance can be derived analytically using simple equilibrium considerations in conjunction with suitable material laws.

242 The analytical model developed in this paper is based on the following assumptions:

- The slip between the steel section and concrete slab is ignored and the distribution of strains throughout the depth of the cross-section is linear, with constant curvature $\kappa$, as shown in Fig. 4.

- The composite beam has a ductile cross-section, with its neutral axis lying within the concrete slab and the strain at the bottom outer fibre of the steel section reaching $\varepsilon_{\mathrm{sh}}$, as shown in Fig. 4, which requires $\mathrm{y}_{\mathrm{csm}} /\left(\mathrm{h}_{\mathrm{c}}+\mathrm{h}_{\mathrm{a}}\right) \leq \varepsilon_{\mathrm{c}, \mathrm{csm}} /\left(\varepsilon_{\mathrm{c}, \mathrm{csm}}+\varepsilon_{\mathrm{sh}}\right)$, where $\mathrm{y}_{\mathrm{csm}}$ is the distance between the plastic neutral axis and the extreme fibre of the concrete slab in compression, $\mathrm{h}_{\mathrm{c}}$ is the depth of the concrete slab, $\mathrm{h}_{\mathrm{a}}$ is the depth of the steel section and $\varepsilon_{\mathrm{c}, \mathrm{csm}}$ is the outer fibre concrete strain.

- The stress-strain relationship for the structural steel is represented by the quad-linear material response of Fig. 1, while the concrete material behaviour is assumed to be rigid

- The stress within the bottom flange of the steel section is assumed to be constant plastic, with plasticity occurring at a stress level of $0.85 f_{\mathrm{cd}}$, where $f_{\mathrm{cd}}$ is the design concrete (cylinder) compressive strength. The tensile strength of the concrete is ignored. 
262 For composite beams with full shear connection under sagging bending moments, deformation capacity will typically be limited by either crushing of the concrete slab or the tensile ductility

264 of the structural steel. In this study, the maximum outer fibre concrete strain is limited by the 265 crushing strain of the concrete $\varepsilon_{\mathrm{cu}}$ (i.e. $\left.\varepsilon_{\mathrm{c}, \mathrm{csm}}=\varepsilon_{\mathrm{cu}}=0.0035\right)$, while the maximum outer fibre 266 strain (at the mid-thickness of the bottom flange) in the steel $\varepsilon_{\mathrm{a}, \mathrm{csm}}$ has been limited to $15 \varepsilon_{\mathrm{y}}$.

The initial step in the determination of the bending resistance is to locate the position of the neutral axis at failure. However, the neutral axis shifts under increasing curvature, and its location at failure will therefore depend on which of the two failure modes (concrete or steel) governs. The general relationship, calculated from the equilibrium of internal forces, between curvature $\kappa_{\mathrm{csm}}$ and neutral axis position $\mathrm{y}_{\mathrm{csm}}$ is given by Eq. (15), in which $\mathrm{b}_{\text {eff }}$ is the effective width of the concrete slab, $A_{a}$ is the cross-sectional area of the steel section, $t_{w}$ is the web thickness of the steel beam and $b_{\mathrm{f}}$ and $t_{\mathrm{f}}$ are the flange width and thickness of the steel beam, respectively.

$$
0.85 f_{\text {cd }} \mathrm{b}_{\text {eff }} \mathrm{y}_{\mathrm{csm}}=f_{\mathrm{y}} \mathrm{A}_{\mathrm{a}}+\left(f_{\mathrm{csm}, \mathrm{a}}-f_{\mathrm{y}}\right) \mathrm{b}_{\mathrm{f}} \mathrm{t}_{\mathrm{f}}+0.5 \mathrm{t}_{\mathrm{w}}\left(f_{\mathrm{csm}, \mathrm{a}}-f_{\mathrm{y}}\right)\left(\mathrm{h}_{\mathrm{c}}+\mathrm{h}_{\mathrm{a}}-\mathrm{y}_{\mathrm{csm}}-\frac{\varepsilon_{\mathrm{sh}}}{\kappa_{\mathrm{csm}}}\right)
$$

Based on the governing values of $\kappa_{\mathrm{csm}}$ and $\mathrm{y}_{\mathrm{csm}}$ and the proposed material model (Fig. 1), the outer fibre stresses in the steel section at failure can be determined from Eq. (16).

$$
f_{\text {csm, a }}=f_{\mathrm{y}}+E_{\mathrm{sh}}\left[\kappa_{\mathrm{csm}}\left(\mathrm{h}_{\mathrm{c}}+\mathrm{h}_{\mathrm{a}}-\mathrm{y}_{\mathrm{csm}}\right)-\varepsilon_{\mathrm{sh}}\right]
$$


284 For the case where concrete crushing governs, the limiting curvature $\kappa_{\mathrm{csm}, \mathrm{c}}$ for concrete failure 285 can be determined from Eq. (17), representing the limiting strain of concrete $\varepsilon_{\mathrm{cu}}$ being reached 286 at the outer concrete fibre.

287

288

$$
\kappa_{\mathrm{csm}, \mathrm{c}}=\frac{\varepsilon_{\mathrm{cu}}}{\mathrm{y}_{\mathrm{csm}}}=\frac{0.0035}{\mathrm{y}_{\mathrm{csm}}}
$$

289

290 Substituting Eqs. (16) and (17) into Eq. (15), the quadratic Eq. (18) can be derived to determine

291 the position of the neutral axis $\mathrm{y}_{\mathrm{csm}, \mathrm{c}}$, in which the coefficients B, C and D are given by Eqs.

292 (19), (20) and (21), respectively.

293

294

$$
\mathrm{By}_{\mathrm{csm}, \mathrm{c}}^{2}+\mathrm{Cy}_{\mathrm{csm}, \mathrm{c}}+\mathrm{D}=0
$$

$$
\mathrm{B}=0.85 f_{\mathrm{cd}} \mathrm{b}_{\mathrm{eff}}-\frac{0.0035}{2} \mathrm{t}_{\mathrm{w}} E_{\mathrm{sh}}\left(1+\frac{\varepsilon_{\mathrm{sh}}}{0.0035}\right)^{2}
$$

$$
\mathrm{C}=0.0035 E_{\mathrm{sh}}\left(1+\frac{\varepsilon_{\mathrm{sh}}}{0.0035}\right)\left[\mathrm{b}_{\mathrm{f}} \mathrm{t}_{\mathrm{f}}+\mathrm{t}_{\mathrm{w}}\left(\mathrm{h}_{\mathrm{c}}+\mathrm{h}_{\mathrm{a}}\right)\right]-f_{\mathrm{y}} \mathrm{A}_{\mathrm{a}}
$$

$$
\mathrm{D}=-0.0035 E_{\mathrm{sh}}\left(\mathrm{h}_{\mathrm{c}}+\mathrm{h}_{\mathrm{a}}\right)\left[\mathrm{b}_{\mathrm{f}} \mathrm{t}_{\mathrm{f}}+\frac{\mathrm{t}_{\mathrm{w}}}{2}\left(\mathrm{~h}_{\mathrm{c}}+\mathrm{h}_{\mathrm{a}}\right)\right]
$$

301

302 When steel failure governs the deformation capacity (i.e. when the strain at the outer steel fibre 303 reaches the limiting strain of $15 \varepsilon_{\mathrm{y}}$ ), the limiting curvature $\kappa_{\mathrm{csm}, \mathrm{a}}$ can be determined from Eq. 304 (22): 


$$
\kappa_{\mathrm{csm}, \mathrm{a}}=\frac{15 \varepsilon_{\mathrm{y}}}{\mathrm{h}_{\mathrm{c}}+\mathrm{h}_{\mathrm{a}}-\mathrm{y}_{\mathrm{csm}, \mathrm{a}}}
$$

308 Similarly, substituting Eqs. (16) and (22) into Eq. (15) results in Eq. (23), which can be used

309 to determine the neutral axis position $\mathrm{y}_{\mathrm{csm}, \mathrm{a}}$ at the point of failure in the steel section.

310

$$
\begin{aligned}
\mathrm{y}_{\mathrm{csm}, \mathrm{a}}= & {\left[f_{\mathrm{y}} \mathrm{A}_{\mathrm{a}}+E_{\mathrm{sh}}\left(15 \varepsilon_{\mathrm{y}}-\varepsilon_{\mathrm{sh}}\right) \mathrm{b}_{\mathrm{f}} \mathrm{t}_{\mathrm{f}}\right.} \\
& \left.+\frac{E_{\mathrm{sh}}}{2}\left(15 \varepsilon_{\mathrm{y}}-\varepsilon_{\mathrm{sh}}\right) \mathrm{t}_{\mathrm{w}}\left(\mathrm{h}_{\mathrm{c}}+\mathrm{h}_{\mathrm{a}}\right)\left(1-\frac{\varepsilon_{\mathrm{sh}}}{15 \varepsilon_{\mathrm{y}}}\right)\right] /\left[0.85 f_{\mathrm{cd}} \mathrm{b}_{\text {eff }}+\frac{E_{\mathrm{sh}}}{2}\left(15 \varepsilon_{\mathrm{y}}-\varepsilon_{\mathrm{sh}}\right) \mathrm{t}_{\mathrm{w}}\left(1-\frac{\varepsilon_{\mathrm{sh}}}{15 \varepsilon_{\mathrm{y}}}\right)\right]
\end{aligned}
$$

313 The lower of $\kappa_{\mathrm{csm}, \mathrm{c}}$ and $\kappa_{\mathrm{csm} . \mathrm{a}}$ defines the governing failure mode. The relationship between the

314 neutral axis position $\mathrm{y}_{\mathrm{csm}}$ and its corresponding curvature $\kappa_{\mathrm{csm}}$ for a typical composite beam,

315 given by Eq. (15), is plotted in Fig. 5 as an example to illustrate the above calculation process.

316 The geometric and material properties employed are: $b_{\text {eff }}=1500 \mathrm{~mm}, \mathrm{~h}_{\mathrm{c}}=120 \mathrm{~mm}, f_{\mathrm{cd}}=35$

$317 \mathrm{~N} / \mathrm{mm}^{2}, f_{\mathrm{y}}=355 \mathrm{~N} / \mathrm{mm}^{2}, E=210000 \mathrm{~N} / \mathrm{mm}^{2}$ and the steel section is a UB $475 \times 152 \times 60$. The

318 strain hardening strain $\varepsilon_{\mathrm{sh}}$ and modulus $E_{\mathrm{sh}}$ were determined from Eqs. (6) and (4), respectively.

319 In this case, at failure, the neutral axis position lies within the concrete slab and the steel section

320 is fully yielded. Fig. 5 shows how the position of the neutral axis moves downwards with

321 increasing curvature, and there is a change in slope as the deformation progresses through the elastic region, outer fibre yielding of the steel and strain hardening of the steel. The points at which the concrete failure criterion (Eq. (17)) and the steel failure criterion (Eq. (22)) intersect with Eq. (15) define the corresponding neutral axis positions and curvatures at failure. For the case illustrated, steel failure is the governing mode. 
Finally, the moment capacity of the composite section, considering the first three stages of the quad-linear material model, featuring both the yield plateau and strain hardening, can be calculated from Eq. (24).

$$
\begin{aligned}
M_{\mathrm{csm}, \mathrm{c}} & =\left(f_{\mathrm{csm}}-f_{\mathrm{y}}\right) \mathrm{b}_{\mathrm{f}} \mathrm{t}_{\mathrm{f}}\left(\mathrm{h}_{\mathrm{c}}+\mathrm{h}_{\mathrm{a}}-\frac{\mathrm{y}_{\mathrm{csm}}}{2}\right)+f_{\mathrm{y}} \mathrm{A}_{\mathrm{a}}\left(\mathrm{h}_{\mathrm{c}}+\frac{\mathrm{h}_{\mathrm{a}}}{2}-\frac{\mathrm{y}_{\mathrm{csm}}}{2}\right) \\
& +\frac{\mathrm{t}_{\mathrm{w}}}{12}\left(f_{\mathrm{csm}}-f_{\mathrm{y}}\right)\left(\mathrm{h}_{\mathrm{c}}+\mathrm{h}_{\mathrm{a}}-\frac{\varepsilon_{\mathrm{sh}}}{\kappa_{\mathrm{csm}}}-\mathrm{y}_{\mathrm{csm}}\right)\left[4\left(\mathrm{~h}_{\mathrm{c}}+\mathrm{h}_{\mathrm{a}}\right)+2 \frac{\varepsilon_{\mathrm{sh}}}{\kappa_{\mathrm{csm}}}-\mathrm{y}_{\mathrm{csm}}\right]
\end{aligned}
$$

The resistances obtained from the proposed analytical method have been compared against a series of experimental results collected from the literature $[4,6]$ on composite beams with full shear connection. The comparisons, shown in Table 3, have been made on the basis of the measured geometric and material properties, with all partial factors set to unity. The proposed method, accounting for strain hardening, may be seen to provide a more accurate prediction of test capacity than the current approach given in Eurocode 4.

\subsection{Partial shear connection}

In the case of composite beams with partial shear connection, the contribution of strain hardening to the cross-section moment capacity cannot be calculated using the analytical method described in Section 3.2. The deformability and finite resistance of the shear connection leads to a more complex arrangement of internal forces in the composite section, with two distinct neutral axes lying within the concrete slab and the steel section. A numerical approach, using the finite element (FE) package ABAQUS [38], was adopted herein to predict the collapse load of composite beams with partial shear connection. The numerical models were initially validated against a series of experimental results and then used to perform parametric studies to generate additional data over a range of steel grades and shear connection ratios. 


\subsubsection{FE model and validation}

351 The FE method has been used in a number of studies to investigate the behaviour of composite beams [39-42]. Among the previous research, a two-dimensional FE model for composite beams has been developed and validated by Queiroz et al. [41]. This two-dimensional model was shown to provide accurate results and was far more efficient than equivalent threedimensional representations in terms of reduced numerical convergence issues and processing times. A similar approach was adopted in this paper. Geometric and material nonlinearities were considered in the model. The steel beam and concrete slab were modelled using quadratic beam elements (B22), while the mechanical shear connectors were simulated using rigid links (CONN2D2) and nonlinear spring elements (SPRINGA), as shown in Fig. 6.

The material properties of the steel beam were represented using the stress-strain curve shown in Fig. 1. In the validation of the two-dimensional FE models against existing tests, the steel reinforcement in the concrete slab was simulated using the *REBAR keyword in ABAQUS, which can be used to add discrete axial reinforcement to beam elements. Note that only longitudinal reinforcement was considered in the FE models for simplicity. An elastic perfectly plastic material model was used for the reinforcement. The nonlinear stress-strain relationship [43] as:

$$
\sigma_{\mathrm{c}} / f_{\mathrm{cm}}=\frac{\mathrm{k}\left(\varepsilon_{\mathrm{c}} / \varepsilon_{\mathrm{cl}}\right)-\left(\varepsilon_{\mathrm{c}} / \varepsilon_{\mathrm{cl}}\right)^{2}}{1+(\mathrm{k}-2)\left(\varepsilon_{\mathrm{c}} / \varepsilon_{\mathrm{cl}}\right)}
$$

372 where $\sigma_{\mathrm{c}}$ is the compressive stress (in $\mathrm{MPa}$ ), $f_{\mathrm{cm}}$ is mean value of concrete cylinder compressive

373 strength (in $\mathrm{MPa}$ ), $\varepsilon_{\mathrm{c}}$ is the compressive strain, $\varepsilon_{\mathrm{cl}}$ is the compressive strain at the peak stress 
$374 f_{\mathrm{cm}}$ and taken as $\varepsilon_{\mathrm{cl}}=\min \left(0.7 f_{\mathrm{cm}}{ }^{0.31}, 2.8\right) \% \mathrm{o}, \mathrm{k}=1.05 E_{\mathrm{cm}} \varepsilon_{\mathrm{cl}} / f_{\mathrm{cm}}$, where the mean value of the secant modulus of elasticity of concrete $E_{\mathrm{cm}}$ (in GPa) is obtained from $E_{\mathrm{cm}}=22 \times\left(f_{\mathrm{cm}} / 10\right)^{0.3}, \varepsilon_{\mathrm{cul}}$ is the ultimate compressive strain and is taken as $\varepsilon_{\mathrm{cul}}=\min \left[2.8+27 \times\left(98-f_{\mathrm{cm}} / 100\right)^{4}, 3.5\right] \%$, and $f_{\text {ctm }}$ is the mean value of the axial tensile strength (in MPa) and may be determined through $f_{\text {ctm }}$ $378=0.3 \times\left(f_{\mathrm{cm}}-8\right)^{2 / 3}$ when $f_{\mathrm{cm}} \leq 58 \mathrm{MPa}$, otherwise $f_{\mathrm{ctm}}=2.12 \times \ln \left(1+f_{\mathrm{cm}} / 10\right)$. The concrete strain at cracking is taken as 0.01 , beyond which the concrete carries zero stress. The stress-strain model for the concrete is illustrated in Fig. 7.

The approach taken to the modelling of the shear connectors is indicated in Fig. 6. The loadslip relationship proposed by Johnson and Molenstra [37] was used to simulate the shear stud connectors, where curve A and a maximum slip $s_{\max }=6 \mathrm{~mm}$ was adopted in the present study. Failure was signified when the designated maximum strains in either of the materials were reached: $\varepsilon_{\mathrm{cul}}=0.0035$ for the concrete and $\varepsilon_{\mathrm{a}, \mathrm{csm}}=15 \varepsilon_{\mathrm{y}}$ for the steel, or when the maximum allowable slip in the shear connectors, defined as $s_{\max }=6 \mathrm{~mm}$, was reached. The Riks solution method was used to trace the nonlinear equilibrium paths of the models and to obtain the peak loading magnitude.

The FE model developed in this sub-section was employed to analyze a series of simply supported composite beams reported in the literature $[4,5,44,45]$. Experimental investigations with a total of 14 composite beams with full shear connection and 5 with partial shear connection were employed herein to validate the FE model. Two typical load versus mid-span deflection curves obtained from the FE model are compared with those obtained experimentally and numerically with a 3D FE model [42], as shown in Fig. 8. 
398 The results indicate that the FE models developed herein are capable of accurately simulating

399 the load-deformation response and ultimate capacity of composite beams with both full shear

400 connection and partial shear connection, with the mean value of the ratio of FE ultimate

401 capacity to test ultimate capacity $\left(N_{\mathrm{FE}} / N_{\mathrm{test}}\right)$ being 0.99 and the COV being 0.054 .

402

403 3.3.2. Parametric analysis and design approach

404 To evaluate the influence of the steel grade and the degree of shear connection $\eta$, which is defined as the ratio of the design value of the compressive normal force within the concrete flange $N_{\mathrm{c}}$ to the design value of the compressive normal force within the concrete flange with

407 full shear connection $N_{\mathrm{c}, \mathrm{f}}, 36$ simply supported composite beams loaded by a point load at mid408 span were analyzed using the validated FE model. The considered steel grades were S275, S355, S420 and S460, and the degrees of shear connection $\eta$ ranged from 0.4 to 1.2. The beam cross-section dimensions (UB305×165×40) and the span length of $6 \mathrm{~m}$ were kept constant, while different steel grades, concrete slabs and grades and levels of shear connections were considered. The basic material parameters and dimensions of the concrete slab are summarized in Table 4. The material models introduced into the FE model are determined according to the proposed equations described in sub-section 2.2 for the steel and to Eurocode 2 for the concrete. The shear connectors were located uniformly along the entire span of the composite beams and their ultimate shear capacity was taken as $119 \mathrm{kN}$ [5]. In the parametric studies, the number of

417 the shear connectors was determined based on the prescribed values of $\eta$ and the computed 418 values of $N_{\mathrm{c}, \mathrm{f}}$. The reinforcement was not considered in the parametric studies; hence 419 conservative predicted capacities may be obtained. Note that the amount of reinforcement provided can have a significant influence on composite beam behaviour [46], in terms of both the ductility and strength, and the reinforcement should be considered in future studies. 
423 Eurocode 4 provides two alternative approaches, namely the equilibrium and the interpolation

424 method, for the design of composite beams with partial shear connection. The former approach

425

426

427 uses equilibrium equations and, considering the maximum force that can be transferred by the shear connection, determines the position of neutral axis within the cross-section and hence the plastic moment resistance, while the interpolation method simply adopts a linear interpolation between the plastic moment resistance of the bare steel section for $\eta=0$ and the full plastic moment resistance of the composite beam for $\eta=1$. Fig. 9 shows a comparison of the maximum moment capacity $\left(M_{\mathrm{FEA}}\right)$ of the 36 beams obtained from the FE model with the results $\left(M_{\mathrm{EC} 4}\right)$ determined using the Eurocode 4 equilibrium method.

It can be seen that, for composite beams with partial shear connection, the ratio of $M_{\mathrm{FEA}} / M_{\mathrm{EC} 4}$ decreases with an increase of the degree of shear connection and the grade. The equilibrium method predicts accurate results when $\eta>0.8$, and conservative ones when $\eta<0$.8. However, the equilibrium method may overestimate the bending capacity of composite beams with high strength steel (S460) because the assumed rigid plastic model overestimates the development of plasticity.

On the basis of the numerical results generated, a tentative approach to calculate the bending capacity of composite beams with partial shear connection, but accounting for strain hardening, is proposed. The adopted approach utilizes the CSM bending resistance of the bare steel section $M_{\text {csm }}$ described in Section 2 for $\eta=0$ and the proposed bending resistance for the composite beams with full shear connection $M_{\mathrm{csm}, \mathrm{c}}$ derived in Section 3.2 for $\eta=1$, in conjunction with an interpolation function for intermediate degrees of shear connection. In Fig. 10, the ratio between $M_{\mathrm{FEA}}$ and $M_{\mathrm{csm}, \mathrm{c}}$ is plotted on the vertical axis and the degree of shear connection $\eta$ is given on the horizontal axis. It can be seen that the composite beams with conventional mild 
steel $\left(f_{\mathrm{y}}<460 \mathrm{MPa}\right)$ exhibit a similar linear trend between $\eta=0.4$ and $\eta=1$, indicating that a

449 bi-linear interpolation function may be used to predict the ultimate capacity of composite 450 beams with partial shear connection allowing for strain hardening, as shown in Fig. 10, where 451 an indicative interpolation line is presented. For composite beams with high strength steel, 452 lower reduction factors may be needed. Clearly a wide range of parameters including different 453 cross-sectional geometries, reinforcement ratios and steel grades need to be considered before the method is suitable for use in practical design; the present study demonstrates the validity of the proposed approach.

\section{Conclusions}

458 Developments to the Continuous Strength Method (CSM) for hot-rolled carbon steel, covering recent refinements, have been described. A quad-linear material model, enabling representation of both the yield plateau and strain hardening, has been proposed and used for the derivation of CSM resistance equations for the compression and bending of hot-rolled carbon steel members. Test data on hot-rolled carbon steel stub columns and beams were used to make comparisons with the CSM and EN 1993-1-1 design provisions. It was shown that the CSM offers improved mean resistance predictions and lower scatter compared with EN 1993-1-1. The method was then extended to composite beams under sagging bending moment, where the influence of strain hardening has been found previously to be significant. For composite beams

467 with full shear connection, a new analytical model has been developed accounting for strain 468 hardening through the proposed material model, and explicit resistance functions have been 469 derived. Comparison of the predictions with 14 test results on composite beams from the 470 literature showed that the proposed analytical equations may be more accurate than the current 471 codified approaches. A two-dimensional FE model was then developed and validated against 472 test results reported in existing studies. Based on subsequently generated numerical parametric 
results, a new design approach was outlined for composite beams with partial shear connection.

474 Additional analyses considering various geometric properties and different reinforcement

475 ratios for composite beams are needed to confirm the wider applicability of the proposed design 476 method to steel-concrete composite beams.

477

\section{Acknowledgements}

479 The financial support provided by the China Scholarship Council (CSC) for the second author's 480 PhD study at Imperial College London is acknowledged.

481

482

\section{REFERENCES}

483

[1] Gardner, L., Saari, N. and Wang, F. (2010). Comparative experimental study of hot-rolled and cold-formed rectangular hollow sections. Thin-Walled Structures, 48 (7), 495-507.

485

486

[2] Liew, A., Boissonnade, N., Gardner, L. and Nseir, J. (2014). Experimental study of hot487 rolled rectangular hollow sections. Proceedings of the Annual Stability Conference, Structural Stability Research Council, March 25-28, 2014, Toronto, Canada.

489

490

[3] Byfield, M. and Nethercot, D. A. (1998). An analysis of the true bending strength of steel beams. Proceedings of the ICE-Structures and Buildings, 128 (2), 188-197.

492

493 [4] Ansoutian, P. (1982). Plastic rotation of composite beams. Journal of the Structural 494 Division, ASCE 108 (3), 643-659.

495

496 [5] Chapman, J. and Balakrishnan, S. (1964). Experiments on composite beams. The Structural 497 Engineer, 42 (11), 369-383. 
498 [6] Chung, K.F. and Chan, C. (2010). A numerical investigation into the effect of strain 499 hardening on the structural behaviour of simply supported composite beams. Proceedings of 500 the 9th Pacific Structural Steel Conference, October 19-22, 2010, Beijing, China, 988-993.

501

502 [7] Gardner, L. and Nethercot, D. A. (2004). Stainless steel structural design: A new approach.

503 The Structural Engineer, 82 (21), 21-28.

504

505 [8] Ashraf, M., Gardner, L. and Nethercot, D. A. (2008). Structural stainless steel design:

506 Resistance based on deformation capacity. Journal of Structural Engineering, ASCE 134 (3), $507 \quad 402-411$.

508

509 [9] Afshan, S. and Gardner, L. (2013). The continuous strength method for structural stainless 510 steel design. Thin-Walled Structures, 68, 42-49.

511

512 [10] Gardner, L. (2008). The continuous strength method. Proceedings of the ICE-Structures 513 and Buildings, 161 (3), 127-133.

514

515 [11] Gardner, L., Wang, F. and Liew, A. (2011). Influence of strain hardening on the behaviour 516 and design of steel structures. International Journal of Structural Stability and Dynamics, 11(5), $517 \quad 855-875$.

519 [12] Liew, A. and Gardner, L. (2015). Ultimate capacity of structural steel cross-sections under 520 compression, bending and combined loading. Structures, 1, 2-11.

521 
522 [13] Su, M. N., Young, B. and Gardner, L. (2014). Testing and design of aluminium alloy 523 cross-sections in compression. Journal of Structural Engineering, 140 (9), Article UNSP 52404014047.

525

526 [14] Schafer, B. W. and Ádány, S. (2006). Buckling analysis of cold-formed steel members 527 using CUFSM: conventional and constrained finite strip methods. Proceedings of the 18th 528 International Specialty Conference on Cold-Formed Steel Structures, October 26-27, 2006, 529 Orlando, Florida, USA, 39-54.

530

531 [15] Seif, M. and Schafer, B. W. (2010). Local buckling of structural steel shapes. Journal of 532 Constructional Steel Research, 66 (10), 1232-1247.

533

[16] EN 1993-1-5. (2006). Eurocode 3: Design of steel structures — Part 1-5: Plated structural 535 elements. European Committee for Standardization (CEN), Brussels.

536

537 [17] Schafer, B. W. (2008). Review: the direct strength method of cold-formed steel member 538 design. Journal of Constructional Steel Research, 64 (7), 766-78.

540 [18] EN 1993-1-1. (2005). Eurocode 3: Design of steel structures - Part 1-1: General rules 541 and rules for buildings. European Committee for Standardization (CEN), Brussels.

543 [19] Wang, F. (2011). A deformation based approach to structural steel design. PhD thesis, 544 Imperial College London, London, UK. 
546 [20] Sadowski, A. J., Rotter, J. M., Reinke, T. and Ummenhofer, T. (2015). Statistical analysis

547 of the material properties of selected structural carbon steels. Structural Safety, 53, 26-35.

548

549 [21] Chan, T. and Gardner, L. (2008). Bending strength of hot-rolled elliptical hollow sections. 550 Journal of Constructional Steel Research, 64, 971-86.

551

552

[22] Kuhlmann, U. (1989). Definition of flange slenderness limits on the basis of rotation 553 capacity values. Journal of Constructional Steel Research, 14, 21-40.

554

[23] Wang, J., Afshan, S., Gkantou, M., Theofanous, M., Baniotopoulos, C. and Gardner, L. (2016). Flexural behaviour of hot-finished high strength steel square and rectangular hollow sections. Journal of Constructional Steel Research, 121, 97-109.

558

[24] Shi, G., Ban, H. and Bijlaard, F. S. (2012). Tests and numerical study of ultra-high strength steel columns with end restraints. Journal of Constructional Steel Research, 70, 236-247.

561

[25] Foster, A. and Gardner, L. (2013). Ultimate behaviour of steel beams with discrete lateral restraints. Thin-Walled Structures, 72, 88-101.

564

[26] D'Aniello, M., Landolfo, R., Piluso, V. and Rizzano, G. (2012). Ultimate behaviour of steel beams under non-uniform bending. Journal of Constructional Steel Research, 78, 144158.

569 [27] Cuk, P., Rogers, D., and Trahair, N. (1986). Inelastic buckling of continuous steel beam570 columns. Journal of Constructional Steel Research, 6, 21-52. 
571 [28] Wilkinson, T. J. (1999). The plastic behaviour of cold-formed rectangular hollow sections.

$572 \mathrm{PhD}$ thesis, The University of Sydney, Sydney, Australia.

573

574 [29] Saloumi, E., Hayeck, M., Nseir, J. and Boissonnade, N. (2015). Experimental 575 characterization of the rotational capacity of hollow structural shapes. Proceedings of the 15 th 576 International Symposium on Tubular Structures, May 27-29, 2015, Brazil, 591-594.

577

578

[30] Shokouhian, M. and Shi, Y. (2015). Flexural strength of hybrid steel I-beams based on 579 slenderness. Engineering Structures, 93, 114-128.

580

581 [31] Nseir, J. (2015). Development of a new design method for the cross-section capacity of 582 steel hollow sections. PhD thesis, Université de Liège, Liège, Belgique.

583

584 [32] Sawyer, H. A. (1961). Post-elastic behaviour of wide-flange steel beams. ASCE Journal 585 of the Structural Division, 87 (8), 43-71.

586

587

[33] Lukey, A. F. and Adams, P. F. (1969). Rotation capacity of wide-flange beams under 588 moment gradient. ASCE Journal of the Structural Division, 95 (6), 1173-1188.

590 [34] Roik, K. and Kuhlmann, U. (1987). Experimentelle ermittlung der rotationskapazität 591 biegebeanspruchter I-profile (Teil 2), Der Stahlbau (56), Heft 12 (in German).

[35] Petersen, Chr. (1988). Berjcht über versuche zur rotationskapazität von walzprofilen in

594 fließgelenken und folgerungen für die fließzonenund fileßgelenktheorie. Stahlbau seminar, 595 Fachhochschule Münster (in German). 
596 [36] EN 1994-1-1. (2005). Eurocode 4: Design of composite steel and concrete structures -

597 Part 1-1: General rules and rules for buildings. European Committee for Standardization 598 (CEN), Brussels.

599

600 [37] Johnson, R. and Molenstra, N. (1991). Partial shear connection in composite beams for 601 buildings. Proceedings of the Institution of Civil Engineers, Part 291 (1), 670-704.

602

603 [38] Abaqus. (2011). Reference manual, version 6.11. Simulia, Dassault Systèmes, France.

604

605 [39] Gattesco, N. (1999). Analytical modelling of nonlinear behaviour of composite beams 606 with deformable connection. Journal of Constructional Steel Research, 52 (2), 195-218.

607

608 [40] Zona, A. and Ranzi, G. (2011). Finite element models for nonlinear analysis of steel609 concrete composite beams with partial interaction in combined bending and shear. Finite 610 Elements in Analysis and Design, 47 (2), 98-118.

611

612 [41] Queiroz, F. D., Queiroz, G. and Nethercot, D. A. (2009). Two-dimensional FE model for 613 evaluation of composite beams, I: Formulation and validation. Journal of 614 Constructional Steel Research, 65 (5), 1055-1062.

615

616 [42] Ban, H. and Bradford, M. (2013). Flexural behaviour of composite beams with high 617 strength steel. Engineering Structures, 56, 1130-1141.

618

619 [43] EN 1992-1-1. (2004). Eurocode 2: Design of concrete structures — Part 1-1: General 620 rules and rules for buildings. European Committee for Standardization (CEN), Brussels. 
621 [44] Vasdravellis, G., Uy, B., Tan, E. L. and Kirkland, B. (2015). Behaviour and design of 622 composite beams subjected to sagging bending and axial compression. Journal of 623 Constructional Steel Research, 110, 29-39.

624

625 [45] Kwon, G., Engelhardt, M. D. and Klinger, R. E. (2011). Experimental behaviour of bridge 626 beams retrofitted with post-installed shear connectors. Journal of Bridge Engineering, ASCE $627 \quad 16,536-545$.

628

629 [46] Loh, H. Y., Uy, B. and Bradford, M. (2004). The effects of partial shear connection in the 630 hogging moment regions of composite beams, Part I-Experimental study. Journal of 631 Constructional Steel Research, 60, 897-91 
Figures:

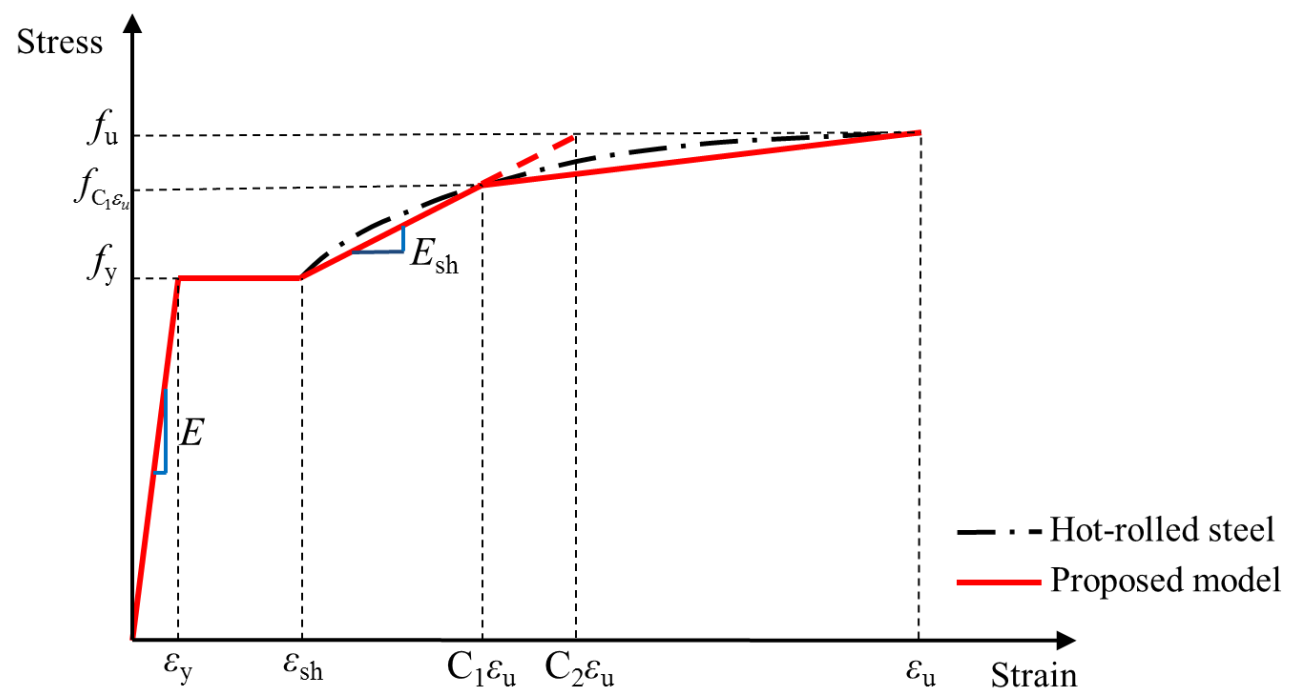

Fig. 1. Typical stress-strain curve for hot-rolled carbon steel and the proposed quad-linear material model. 


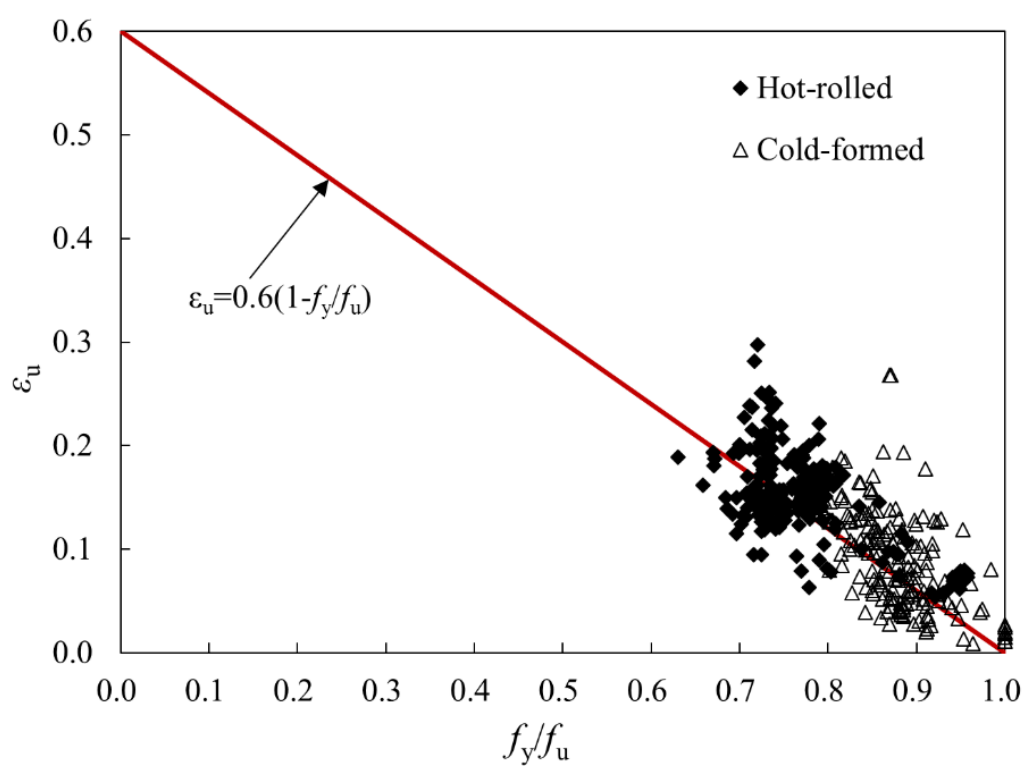

Fig. 2. Predictive expression for $\varepsilon_{\mathrm{u}}$ for hot-rolled (and cold-formed) carbon steels. 


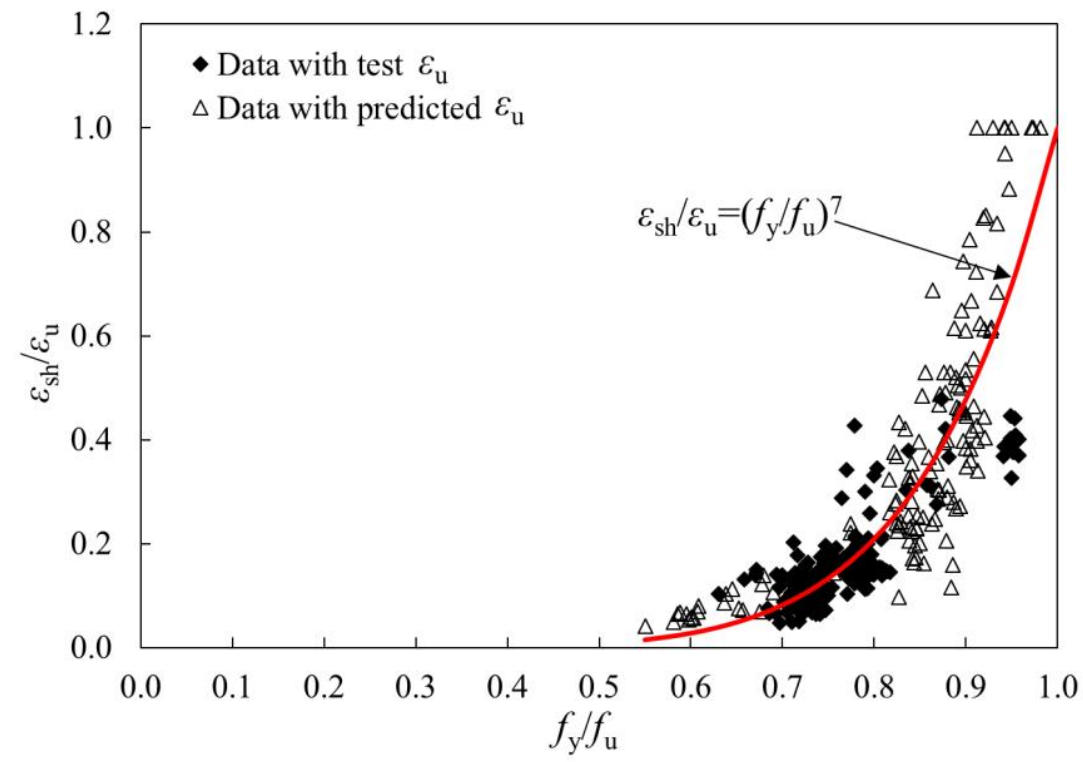

Fig. 3. Predictive expression for $\varepsilon_{\mathrm{sh}}$ for hot-rolled carbon steels. 


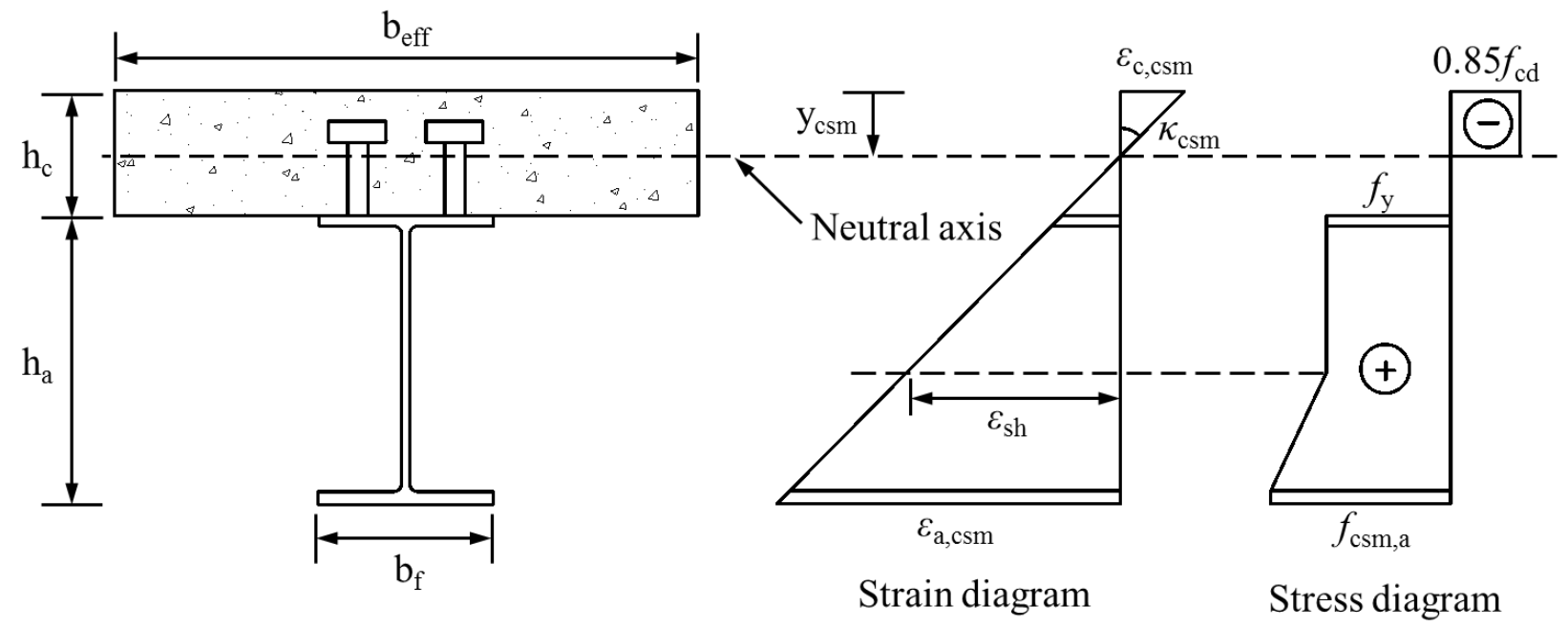

Fig. 4. Strain and stress distributions for a composite beam with full shear connection and the proposed material model. 


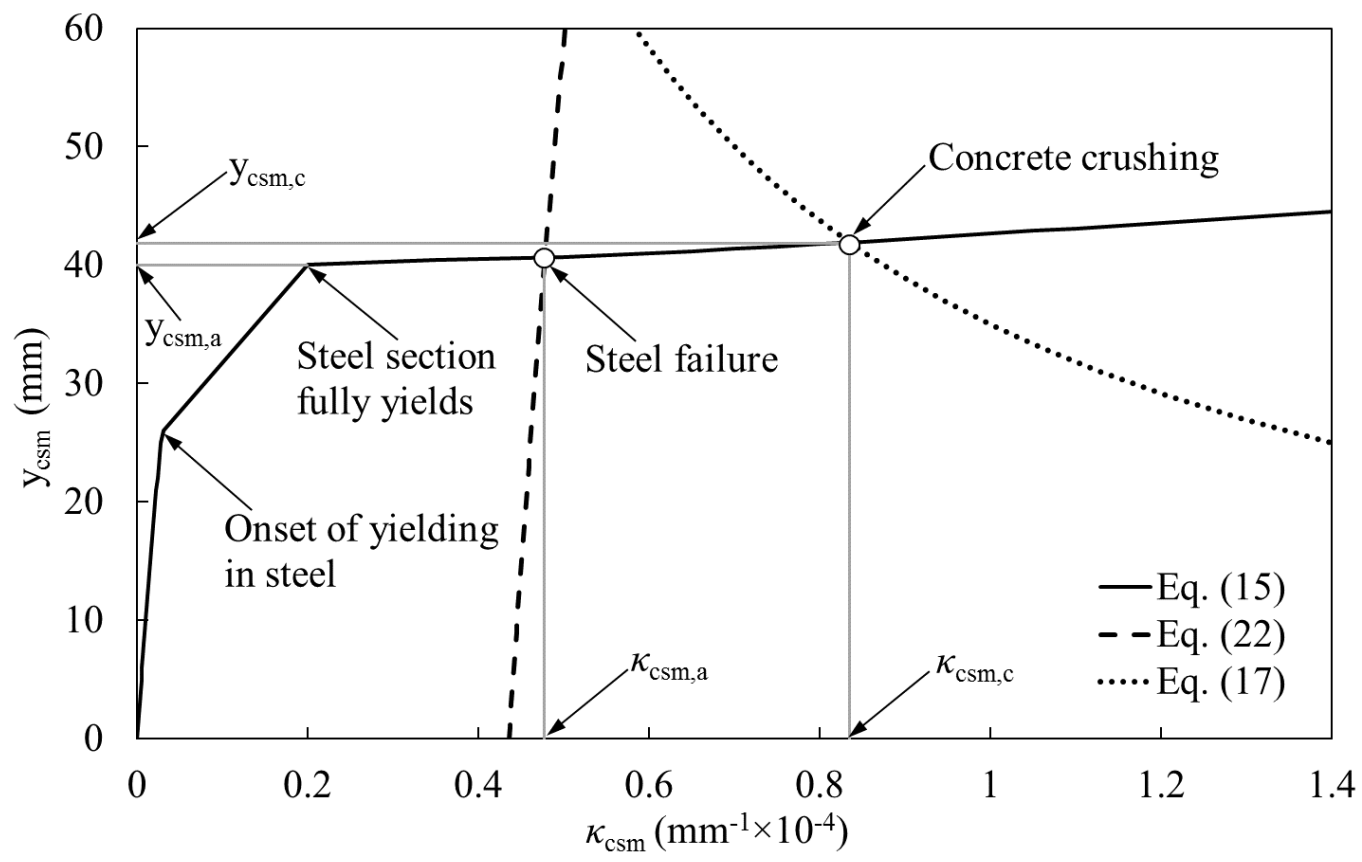

Fig. 5. Relationship between neutral axis position $\mathrm{y}_{\mathrm{csm}}$ and curvature $\kappa_{\mathrm{csm}}$. 


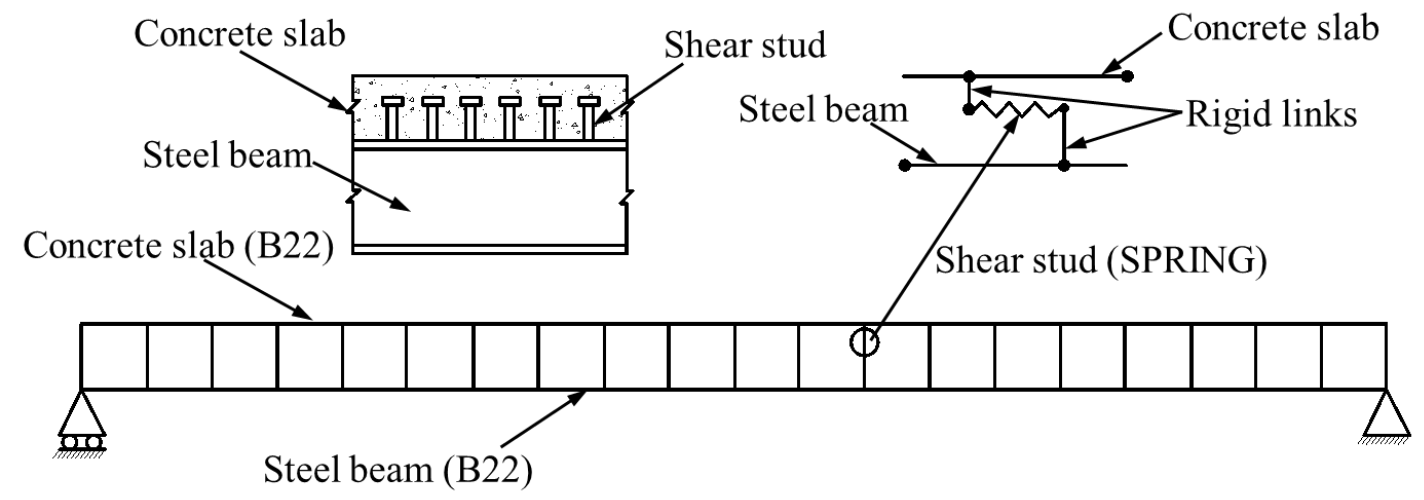

Fig. 6. Finite element types used in composite beam model. 


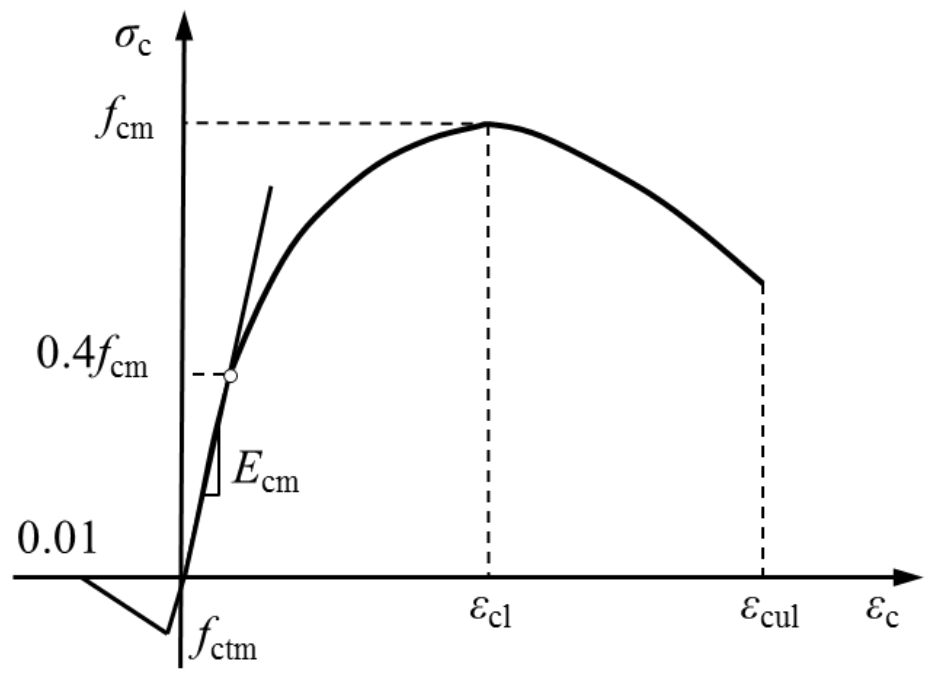

Fig. 7. Stress-strain relationship of concrete material employed in FE model. 


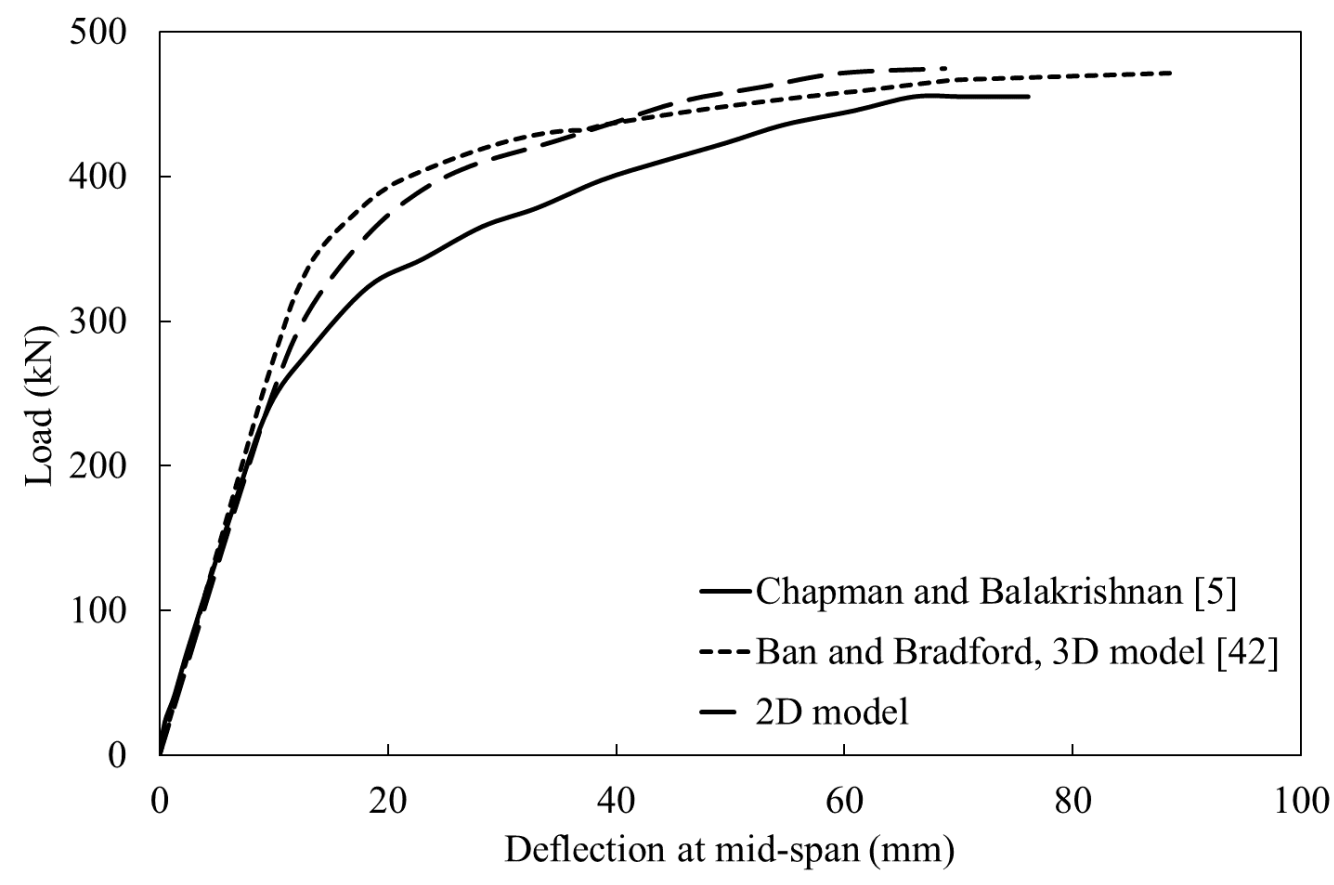

(a) Composite beam A5 with full shear connection

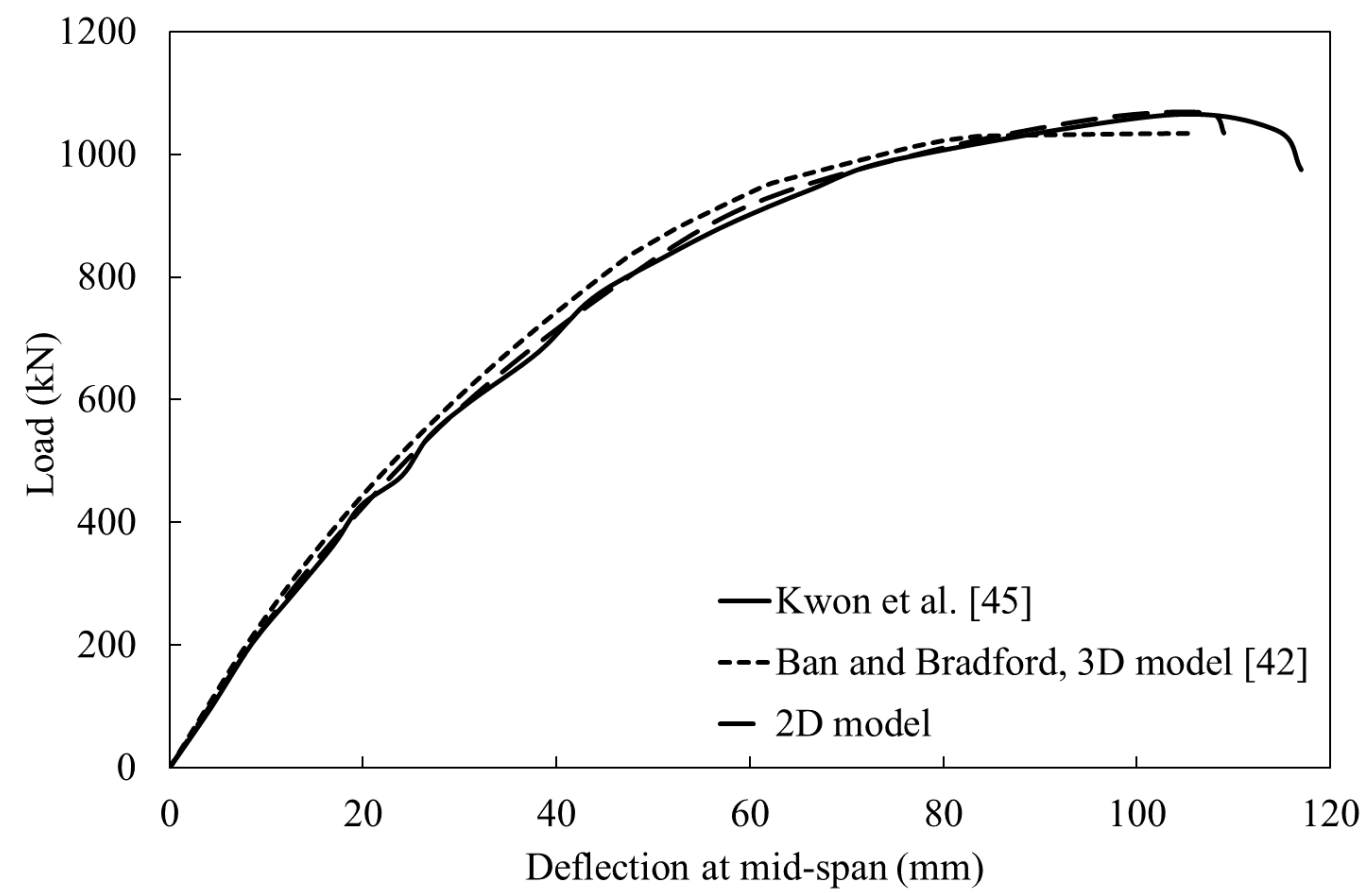

(b) Composite beam HASAA-30BS with partial shear connection Fig. 8. Comparison of load-deflection curves from FE models and experiments. 


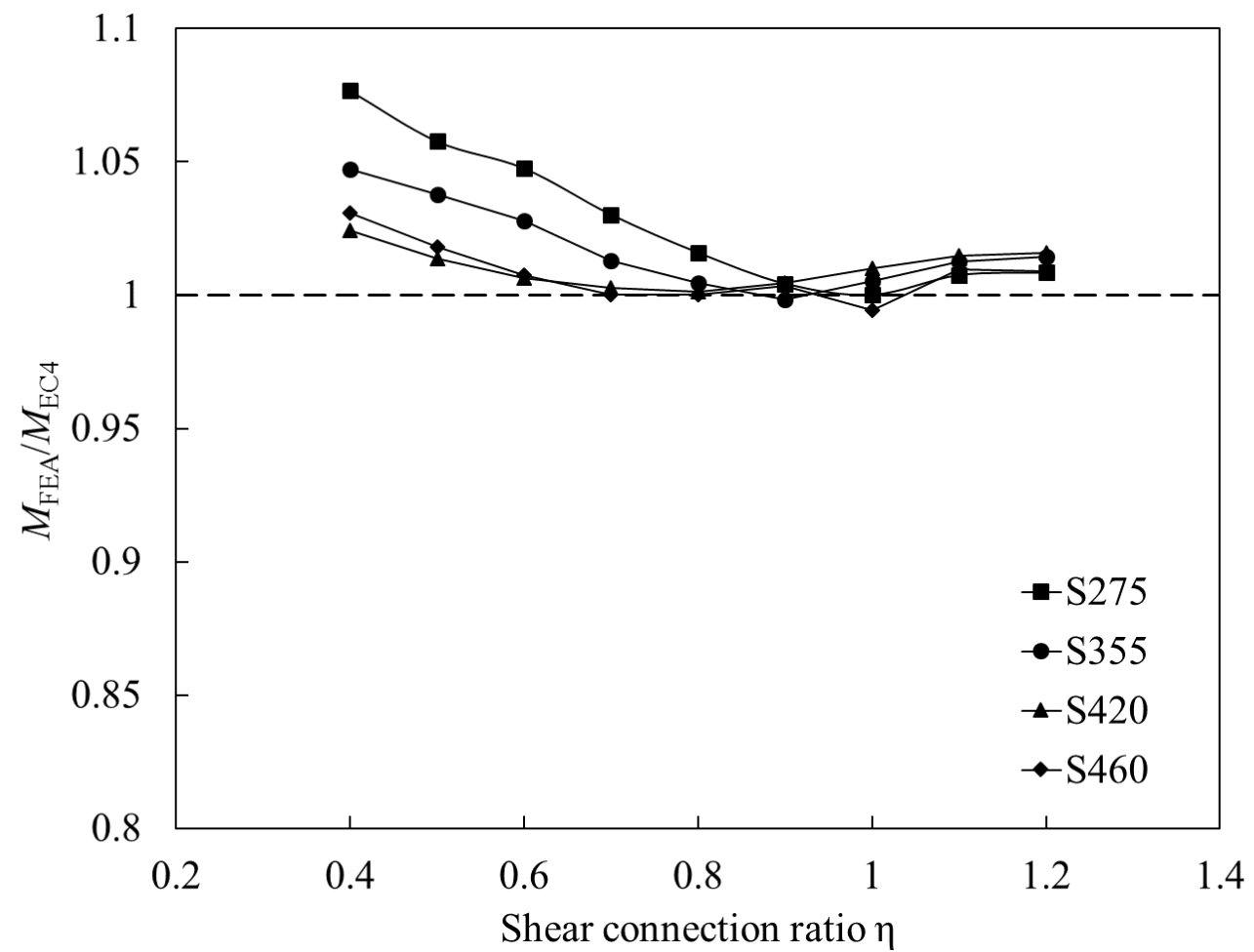

Fig. 9. Comparison of bending strength of composite beams from FE model and EC4. 


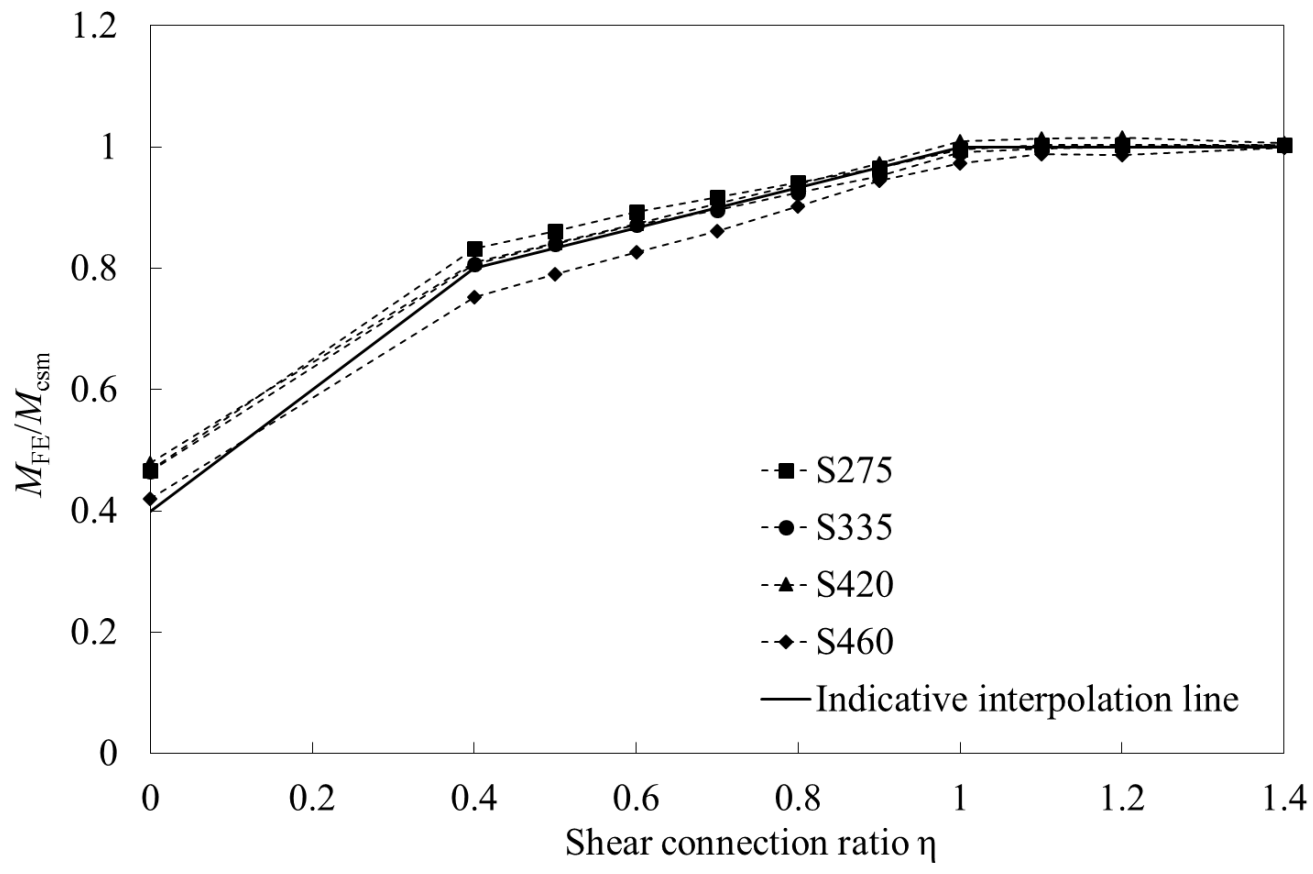

Fig. 10. Indicative interpolation function for composite beams with partial shear connection. 
Tables:

Table 1: CSM coefficients $\alpha$ and $\beta$ for use in bending resistance functions.

\begin{tabular}{ccccc}
\hline & \multicolumn{2}{c}{$\alpha$} & \multicolumn{2}{c}{$\beta$} \\
\cline { 2 - 5 } Axis of bending & Major & Minor & Major & Minor \\
\hline I-sections & 2 & 1.2 & 0.1 & 0.05 \\
SHS/RHS & 2 & 2 & 0.1 & 0.1 \\
\hline
\end{tabular}


Table 2: Comparison between ultimate test capacities and design (CSM and EC3) predictions for cross-section in compression or bending.

\begin{tabular}{ccccccc}
\hline & \multicolumn{2}{c}{ Compression resistance } & \multicolumn{4}{c}{ Bending resistance } \\
\cline { 2 - 7 } & $N_{\text {test }} / N_{\text {EC }}$ & $N_{\text {test }} / N_{\text {csm }}$ & \multicolumn{2}{c}{$M_{\text {test }} / M_{\text {EC }}$} & \multicolumn{2}{c}{$M_{\text {test }} / M_{\text {csm }}$} \\
& & & Class 1 \& 2 & Class 3 & Class 1 \& 2 & Class 3 \\
\hline Mean & 1.07 & 1.06 & 1.18 & 1.17 & 1.16 & 1.08 \\
COV & 0.08 & 0.07 & 0.10 & 0.10 & 0.09 & 0.08 \\
\hline
\end{tabular}


Table 3: Comparison between ultimate test moment capacities and design predictions (CSM and EC4) for composite beams.

\begin{tabular}{cccc}
\hline & $M_{\mathrm{EC}} / M_{\text {test }}$ & $M_{\mathrm{csm}, \mathrm{c}} / M_{\text {test }}$ & $M_{\mathrm{csm}, \mathrm{c}} / M_{\mathrm{EC}}$ \\
\hline Mean & 0.92 & 0.97 & 1.05 \\
COV & 0.05 & 0.06 & - \\
\hline
\end{tabular}


Table 4: Concrete slab dimensions and material properties for parametric studies.

\begin{tabular}{ccccc}
\hline $\begin{array}{c}\mathrm{b}_{\text {eff }} \\
\mathrm{mm}\end{array}$ & $\begin{array}{c}\mathrm{h}_{\mathrm{c}} \\
\mathrm{mm}\end{array}$ & $\begin{array}{c}f_{\mathrm{y}} \\
\mathrm{N} / \mathrm{mm}^{2}\end{array}$ & $\begin{array}{c}f_{\mathrm{u}} \\
\mathrm{N} / \mathrm{mm}^{2}\end{array}$ & $\begin{array}{c}f_{\mathrm{cm}} \\
\mathrm{N} / \mathrm{mm}^{2}\end{array}$ \\
\hline 1500 & 120 & 275 & 390 & 30 \\
1500 & 120 & 355 & 490 & 35 \\
1500 & 120 & 420 & 520 & 35 \\
1500 & 150 & 460 & 540 & 40 \\
\hline
\end{tabular}

